\title{
DE MONSTRUOS, PRESAS DE CACERÍA Y PRESOS EN LA NOVELA TRÁGAME TIERRA DE LIZANDRO CHÁVEZ
}

\author{
Verónica Ríos Quesada
}

\section{(c) $(7)(9)$}

Esta obra está bajo una licencia Creative Commons 



\title{
DE MONSTRUOS, PRESAS DE CACERÍA Y PRESOS EN LA NOVELA TRÁGAME TIERRA DE LIZANDRO CHÁVEZ
}

\author{
MONSTERS, PREYS AND PRISONERS IN LIZANDRO CHÁVEZ'S \\ NOVEL TRÁGAME TIERRA
}

Verónica Ríos Quesada

\begin{abstract}
RESUMEN
La novela de Lizandro Chávez Trágame tierra (1969) representa dos hitos literarios: ser la primera novela contemporánea centroamericana y ser la primera novela sandinista. En este artículo interesa analizar la representación de la otredad política, manteniendo presente esa doble inserción historiográfica. Por una parte, el texto plantea una deconstrucción de la asociación política-monstruosa común en las novelas regionalistas, de la dictadura y las novelas bananeras que preceden al ciclo revolucionario en Centroamérica. Por otra parte, el texto, a diferencia de los textos revolucionarios, no se caracteriza por marcar la subjetividad heroica del revolucionario ni por construir la montaña como espacio de transformación. En vez de haber un marco referencial de regularidades contra el cual proyectar el fenómeno para destacar su anomalía, lo que se presenta es la imposibilidad de definir un código ideológico que integre nociones elementales de lo bueno/ lo malo, lo positivo/lo negativo y que, así, nos permita una clara definición de lo monstruoso de la otredad política. De esa manera la otredad política adquiere rasgos monstruosos desde ambos bandos: somocista y sandinista. El futuro de la revolución y la implantación de una nueva sociedad resultan problemáticos, pues lo monstruoso es familiar, está entre nosotros.
\end{abstract}

Palabras clave: otredad política, literatura centroamericana, Trágame tierra, Chávez-Lizandro, literatura revolucionaria.

\begin{abstract}
The novel Trágame tierra [Swallow Me Earth] (1969), by Lizandro Chávez, represents two key moments in literature: it was the first contemporary Central American novel and the first Sandinista novel. This article analyzes the representation of political otherness, whilst taking into consideration this double historiographical placement. On the one hand, the text deconstructs the politicalmonstrous association that is common to regional novels, dictatorship novels, and banana novels that precede the Revolutionary cycle in Central America. On the other hand the text, as opposed to other revolutionary texts, does not possess the characteristic of highlighting the heroic subjectivity of the revolutionary individual, nor of constructing the mountains as a space of transformation. Instead of having a background of regularities against which to project the phenomenon in order to underline its anomaly, it presents the impossibility of defining an ideological code that integrates elemental notions of good/evil, positive/negative and, thus, allows us a clear definition of the monstrosity of political otherness. In this manner, political otherness acquires monstrous traits from both sides: Somocista and Sandinista. The future of the Revolution and the establishment of a new society turn out to be problematic, due to the fact that monstrosity is familiar, it is among us. Key words: political otherness, Central American literatura, Trágame tierra, Chávez-Lizandro, revolutionary literature.
\end{abstract}

Dra. Verónica Ríos Quesada. Universidad de Costa Rica. Profesora Escuela de Filología y Lingüística. Costa Rica. Correo electrónico: veronica.ucr@ucr.ac.cr

Recepción: 16- 07- 2015

Aceptación: 20- 07- 2015 


$$
\begin{array}{r}
\text { Guardo tus palabras } \\
\text { y tu postrera ansiedad } \\
\text { por mi destino, } \\
\text { porque la historia no te permitió } \\
\text { vislumbrar este momento, } \\
\text { mucho menos comprenderlo. } \\
\text { Vidaluz Meneses ("Última postal a mi padre General Meneses", 1982) }
\end{array}
$$

\section{Introducción}

La novela de Lizandro Chávez Trágame tierra, publicada en México en 1969 y finalista del premio Seix Barral, representa dos hitos literarios: ser la primera novela contemporánea centroamericana después de Asturias (Vargas, 2003, pp. 112-113) y ser la primera novela revolucionaria ligada con la lucha antisomocista (Rodríguez, 1988, p. 117). Sin embargo, pese a sus múltiples atributos, paradójicamente ha pasado casi inadvertida por la crítica. En gran parte, esto se debe justamente a su asociación con la literatura de corte comprometido, pues con el paso del tiempo y la caída de las utopías de la izquierda de los años 60 y 70, dicha literatura ha caído en el olvido tanto del público como de la historiografía académica. Surge entonces el cuestionamiento con respecto a la posibilidad de estudiarlas desde el contexto político-cultural del presente y desde nuevos horizontes teóricos, con el fin de superar el determinismo del contexto político-histórico de su gestación (Perkowska, 2013/2014, p. 10).

Particularmente en el caso de esta novela, Leonel Delgado señala la importancia de un (re)establecimiento genealógico del texto (Delgado, 2013/2014, pp. 3-4) y, en ese sentido, me interesa explorar en este artículo la representación de la otredad política, a sabiendas justamente de que se rompe con las novelas regionalistas anteriores y, por otra parte, se conecta con la literatura revolucionaria posterior. Adelantando la tesis de este artículo, planteo que por una parte el texto deconstruye la asociación política-monstruosa común en las novelas regionalistas, de la dictadura y las novelas bananeras que preceden al ciclo revolucionario en Centroamérica. Además, se suelen acompañar de la conquista del espacio también visto como otredad monstruosa y de una subjetividad heroica, característica fundamental en la literatura revolucionaria siguiente. Por otra parte, el texto, a diferencia de los textos revolucionarios, no se caracteriza por marcar ese heroísmo del revolucionario ni por construir la montaña como espacio de transformación.

En ese sentido, esta novela propone un acercamiento muy particular a la representación de la otredad política. El protagonista revolucionario, Luciano Pineda, no se construye realmente como héroe ni quienes se asocian con la dictadura somocista se presentan como monstruos. Además, se deja de lado el recurso de la animalización tanto de las personas como del espacio. A través de la novela se revela un esfuerzo constante por circunscribir la problemática no resuelta de la otredad política, de la posibilidad de un hombre nuevo y una nueva sociedad al terreno de lo humano.

Dicho de otro modo, lo monstruoso no depende en este caso del incumplimiento de las leyes de la naturaleza y de la deformidad física. Más bien la condición de lo monstruoso se presenta a través de la ambigüedad que genera el deseo de ruptura con el orden somocista, con esas reglas sociales. Desde ese punto de vista es importante tomar en cuenta que no se presenta en esta novela un frente sandinista plenamente constituido, sino más bien la aspiración de cambio todavía sin un norte claramente definido. Se explota ese momento de expectativa y 
de no saber qué sucederá para plantear la extrañeza que despiertan quienes persiguen alterar la ley existente. A continuación, dedico la primera sección del artículo al análisis de la subjetividad de Luciano Pineda, el protagonista revolucionario de la novela, para después pasar a explorar la representación del espacio y, finalmente, en la última sección, estudiar lo monstruoso moral de Luciano.

\section{Dudosa subjetividad heroica}

Como rasgo común de la literatura revolucionaria centroamericana, Arturo Arias señala la importancia de la subjetividad heroica. Retomando lo estipulado por Ileana Rodríguez (1988) y Saldaña-Portillo (2003), indica que la narrativa de la revolución fue también la narrativa de la construcción del yo (Arias, 2013/2014, p. 16). Se trata de una característica que, en realidad, se puede rastrear desde antes de dicho ciclo en la literatura centroamericana, pues como señala el historiador Dennis Arias, en el caso del militante comunista y escritor costarricense Carlos Luis Fallas, su metamorfosis ocurrió escribiendo "la experiencia política de la rebelión" (Arias, 2012, p. 59). Asimismo, esa escritura de corte autobiográfico, testimonial incluso, revela un heroísmo ligado a una colectividad. Si bien este posicionamiento fue común para un gran número de escritores, no lo es para Chávez, pues su novela no explota esa vena testimonial, autobiográfica y no utilizó su escritura para justificar o presentarse como líder y menos aún para dar por sentado su papel histórico como letrado.

Desde ese punto de vista, las técnicas literarias utilizadas por Chávez en Trágame tierra cobran una importancia significativa. Para empezar, rompe absolutamente con la monoglosia característica de textos testimoniales posteriores como La montaña es algo más que una inmensa estepa verde de Omar Cabezas. No se trata de una novela enfocada únicamente desde el punto de vista del guerrillero, del revolucionario o del líder. Se alternan tres planos relacionados respectivamente con Plutarco Pineda, Luciano Pineda y César Barrantes. Los dos primeros son padre e hijo y el tercero, ahijado de Plutarco y contemporáneo de Luciano. La relación padre-hijo presenta una profunda brecha generacional ideológica: el padre no colaboró con la lucha de Augusto César Sandino y anhela la construcción del canal de Nicaragua para enriquecerse, mientras que el hijo aborrece al padre por su falta de compromiso político y se une a la insurrección incipiente contra el régimen somocista. El tercer plano se desarrolla en el Caribe nicaragüense y César se desenvuelve en lo que sería el espacio doméstico de la familia Pineda y, de cierta manera, ocupa el espacio dejado por Luciano en esa dinámica.

A la sociedad fracturada, la novela responde por medio de la polifonía. Las voces de Luciano y Plutarco compiten entre sí y se presentan también otras voces y un recurso sumamente interesante, suerte de coro griego, en la figura del Poeta descalzo. Como indica Vargas, la novela de Chávez muestra claramente una superación del regionalismo y una clara conciencia escritural. Señala las técnicas narrativas como monólogo interior, pluralidad de voces, dislocación de tiempo cronológico y la fragmentación. Concluye que, a través de ellas, se da un tratamiento particular a la realidad histórica y se inserta a los personajes en la problemática humana (Vargas, 2003, pp. 112-113).

Por otra parte, es importante destacar el proceso de radicalización de Luciano, pues dista mucho del recorrido de otros revolucionarios. Para empezar, su ruptura con el orden somocista pasa por la educación como aparato ideológico. Plutarco hace pasar a la familia por sacrificios gigantescos por enviar a Luciano, el único hombre, a estudiar a la capital al instituto más prestigioso. La intención era que allí corrigiera "esas pequeñas inconformidades" 
que Luciano había empezado a desarrollar. El narrador se refiere a la lectura autoimpuesta de libros que lo lleva a la conclusión de que Nicaragua debe de transformarse y ese cambio supone la caída de Somoza y la expulsión de la influencia estadounidense en la vida sociopolítica. Sin embargo, su paso por el instituto en vez de amilanar esas impresiones, solo las confirma. Su proceso no lo lleva a una filiación ideológica de izquierda, por ejemplo. Admira a Sandino, pero no se trata de un Sandino que ya pasó por el proceso de captación que realiza Carlos Fonseca Amador, ${ }^{1}$ sino del Sandino que su padre no quiso apoyar. Se trata de un Sandino tomado de los libros, pues no hay en el texto contacto entre Luciano y antiguos sandinistas. Como bien lo resume Leyva: "En su caso no fue el padecimiento en carne propia de la desigualdad económica y social, no fue la pobreza ni la lucha de clases lo que le empujó a la violencia sino su sentido de la moralidad" (Leyva-Carías, 2002, p. 114), punto por retomar en la tercera sección.

En términos temporales, la novela muy hábilmente se sitúa entonces en la coyuntura en la que convergen un padre antisandinista, asociado con el orden somocista y proimperialista de los años veinte y treinta y, por otra parte, un hijo que se suma a la incipiente organización revolucionaria. Como indica Rodríguez, la crisis político-ideológica se lleva directamente al terreno familiar (Rodríguez, 1988, p. 117). Supone un planteamiento muy distinto al de La montaña es algo más, pues en la novela de Chávez el protagonista no establece conexiones con los sandinistas originales. No hay una continuidad histórica como sí se presenta en el testimonio de Cabezas. Dicho de otra manera, en Trágame tierra, Sandino como referente político pertenece a un pasado ya lejano. Lo que permanece es el orden social somocista que encarna el padre, Plutarco Pineda. Como resultado, la fractura político-familiar de Trágame tierra da la impresión de ser insalvable justamente porque solo permite posturas opuestas.

Luciano tiene claro quiénes son los enemigos, sabe que la violencia es el medio, pero no puede vislumbrar cómo darle forma a esa radicalización. A diferencia de los protagonistas de textos revolucionarios escritos cuando ya el entrelazamiento entre estética y política estaba más definido en función de la lucha sandinista, como en ¿Te dio miedo la sangre? de Sergio Ramírez, Luciano no tuvo oportunidad de perfilarse como intelectual reposado y racional. Sin embargo, es capaz de una acción simbólica de peso: cambiarse el nombre. Había sido bautizado Ronald Pineda y a fuerza de insistencia logra que todos lo llamen Luciano "con cierta alegría de pisotear la voluntad del progenitor" (Chávez, 2012, p. 18).

Retomando el viaje del héroe y narrativas similares cuyo calco se presenta en las textualidades revolucionarias, el protagonista debe de superar los obstáculos, dominar al monstruo para erigirse así en vencedor y, en el caso de las figuras guerrilleras, esto significa culminar un proceso de virilización. En este caso, a diferencia de los protagonistas de novelas como ¿Te dio miedo la sangre? de Sergio Ramírez, Los compañeros de Marco Antonio Flores y Caperucita roja de Manlio Argueta (García, 2013), el personaje de Luciano se mantiene absolutamente alejado de cualquier relación con el sexo opuesto, ya sea amorosa, casual o pagada. ${ }^{2}$ Simplemente no hay un objeto de deseo. Luciano no comparte el gusto celebrado de otros protagonistas guerrilleros -incluso heredado de sus padres, a pesar de la brecha ideológica entre ellos- por las mujeres y el alcohol. Su compromiso con la causa es absoluto, no necesita potenciarse gracias a fracasos amorosos, como se da en La montaña es algo más que una inmensa estepa verde (Barbas-Rhoden, 1999).

Dado lo incipiente del movimiento no tiene una audiencia constituida. No hay para quién ser héroe y/o mártir. En ese sentido, su no heroización pasa por una representación de su muerte 
poco llamativa. A diferencia del célebre cuento argentino "El matadero" de Esteban Echeverría, por ejemplo, no hay ni feminización del cuerpo ni metáforas sexuales. Su cuerpo no es ultrajado y tampoco es animalizado en la violencia verbal que se ejerce contra él. Cuando lo encarcelan y torturan, se describe al vuelo lo sucedido y el único diálogo que se incluye detalla un evento menor si lo comparamos con la envergadura de las torturas sufridas. Simplemente Luciano ya no aguanta las ganas de orinar y, ante su mirada suplicante, el guarda le dice "Pues orínese" (Chávez, 2012, p. 212). Definitivamente es una postura muy diferente a la que se asume en textos del escritor y periodista Pedro Joaquín Chamorro, quien en sus libros Los Somoza. Estirpe sangrienta (1958) y Diario de un preso (1962) se basa en su experiencia personal como preso y no deja detalles a la imaginación. Paralelamente, no se erige un cuerpo místico, trascendental. Ni siquiera se narra su ejecución. Por eso, Luciano no logra convertirse, ni siquiera por un instante, en héroe trasgresor en el sentido de Yuri Lotman, es decir, en un héroe capaz de penetrar en un espacio prohibido para destruir allí el orden regente (Jing, 2010, pp. 97-124).

Posiblemente su acto más heroico sea no huir una vez que su campamento guerrillero cerca de la frontera entre Honduras y Nicaragua es descubierto. Como señala Leyva, tanto Luciano como el protagonista de la novela de Sergio Ramírez ¿Te dio miedo la sangre?, toman la decisión de quedarse en Nicaragua después de que fracasa la ofensiva de El Chaparral ${ }^{3}$ que ficcionalizan ambos textos. Luciano deja de lado la fantasía temporal que lo ha asaltado: "un automóvil, una mujer, una casa, y varios hijos que en la escuela serían medio extranjeros" (Chávez, 2012, p. 193), y cruza nuevamente hacia Nicaragua. En palabras de Leyva, así se revela ese proceso de transición "desde su antiguo mundo y su clase, hacia unas actitudes y unos comportamientos revolucionarios" (Leyva, 2002, p. 107).

\section{Anclaje en el espacio intervenido}

Nuevamente al querer establecer las conexiones genealógicas de Trágame tierra, es importante retomar las características en cuanto al manejo del espacio tanto de la novela regionalista como de la literatura revolucionaria posterior. En el caso de la primera, como señala Schmidth-Welle:

\footnotetext{
Por una parte, el interior de los respectivos países se representa como la cuna de la identidad nacional, el lugar del origen, el centro de la "verdadera" identidad cultural, y como el marcador de la diferencia identitaria con respecto a la conquista, la colonización y la dependencia económica, cultural y política. Por otra, este lugar del origen cultural se presenta también como el núcleo de la barbarie que tiene que superarse para llegar plenamente a la modernidad y al desarrollo socioeconómico deseados. Esta oposición se traduce también a las representaciones frecuentes de las diferencias entre ciudad y campo. Las novelas del regionalismo "clásico" se convierten de esta manera en un campo de batalla simbólico entre civilización y barbarie, entre modernidad y diferencia. (Schmidt-Welle, 2012, p. 122)
}

Asimismo, esta lucha entre civilización-barbarie también se extiende a la novela bananera. Sin embargo, a diferencia de la novela regionalista, ese espacio caribeño no se plantea como "cuna de la identidad nacional". Al respecto, señalan Mackenbach y Grinberg particularmente sobre Mamita Yunai de Carlos Luis Fallas, que si bien es cierto la novela abre la representación espacial hacia el Caribe, lo hace en función de la exclusión de negros, indígenas y mujeres, pues su enfoque es darle primacía a la condición de explotados y oprimidos (Grinberg y Mackenbach, 2006, p. 171). En esa misma dirección apunta Dennis Arias al señalar que la estructuración metafórica del Caribe como "inhóspito lugar monstruoso" da pie para la “visualización heroica del yo" en la novela de Fallas (Arias, 2012, p. 59). 
Por otra parte, ya en el ciclo de los textos revolucionarios, el espacio montañoso o la selva incluso se transforman. Pasan de ser sinónimo de alienación a renacimiento. El espacio indómito simboliza entonces la configuración del llamado "hombre nuevo". Se rompe entonces con la dicotomía civilización-barbarie porque es la civilización, tal y como se ha entendido hasta ese momento, la que en realidad conduce a la barbarie social. En otras palabras, ese espacio que significaba barbarie en textos como La vorágine de Eustasio Rivera o Prisión verde de Ramón Amaya se resignifica. Al respecto del testimonio sandinista La montaña es algo más, Laura Barbas indica que Cabezas plantea su paso de novato a guerrillero en la montaña como "espacio significativo por su marginalidad en la economía nicaragüense y por las connotaciones religiosas" (Barbas-Rhoden, 1999, p. 68).

Trágame tierra se sitúa justamente entre estas dos maneras de representar el espacio. No hay tal espacio monstruoso, ni siquiera la naturaleza lo es y, por otra parte, la transformación que sufre en la montaña funciona a medias, como veremos a continuación.

En primer lugar es importante subrayar que el Caribe no es espacio monstruoso. Es más bien el lugar de origen de Luciano y de todos los personajes importantes del texto. Al respecto es vital retomar el trabajo de Leonel Delgado con respecto a la representación del Caribe en la literatura nicaragüense. Señala Delgado que hay tres maneras de ver el Caribe:

\footnotetext{
1) como Paraíso interrumpido por el cruce de la civilización, 2) como maquinaria de producción identitaria que interrumpe la visión general de lo nacional, pero que deviene también lo Otro absoluto (abyecto, desviado, animalizado), 3) como raíz racial de lo nacional que imperiosamente debe ser rescatada en el contexto de la globalización para ser disciplinada e inventariada (como 'mulatidad'). (Delgado, 2011, p. 6)
}

En Trágame tierra no se presenta ninguna de las tres opciones y, en el plano de interés para este artículo, es decir el de Luciano, no hay de parte del personaje ninguna reflexión acerca del papel de la costa caribeña y su rol en la nación nicaragüense. Se podría decir que no pone en duda la inserción de dicho territorio en la concepción de comunidad imaginada. Eso sí, el Caribe como tal sí tiene un papel preponderante en el texto a través del plano abanderado por César Barrantes. Al respecto, Delgado señala que dicha línea pone en jaque la idea de una escritura de lo nacional, pues su incorporación supone la presencia de una fuerte memoria transcaribeña y sus ramificaciones políticas. César, a diferencia de sus hermanos, señala Delgado, "elabora un contradictorio proyecto de arraigo territorial" (2011, p. 9) centrado en el Caribe. En comparación con Luciano, se podría decir que este último plantea también ese proyecto pero de una manera conceptual y a escala nacional; mientras que César lo ejecuta regionalmente y, como señala Delgado, enunciando "la necesidad de articulación de lo reprimido en la historia nacional" (2011, p. 11).

En segundo lugar, después de abandonar el hogar y el estudio en la capital, Luciano decide incorporarse a las filas de la revolución y pasar por un proceso de entrenamiento en la montaña. En un texto como La montaña es algo más, el paso por la montaña se convierte en un espacio de renovación. Allí es donde realmente se despoja de su antigua forma de comprender qué significa ser humano. En contraposición, Luciano no tiene tiempo de aprender. Lo que hubiera podido interpretarse como el viaje del héroe queda trunco. Al cabo de unos cuantos días, su campamento es descubierto y se salva de ser ejecutado en el acto porque la brigada de caza, de la cual formaba parte, se había alejado de la base para buscar comida.

Al inicio de su entrenamiento guerrillero, el hijo de Plutarco no es capaz de matar a una mula enferma para dar de comer al regimiento, no logra superar "la incontenible repugnancia por las llagas que la bestia tenía en el lomo” (Chávez, 2012, pp. 167-168). Además, después de cazar una boa, Luciano experimenta su muerte como espectáculo monstruoso 
(Chávez, 2012, p. 173). La emergencia de la situación lo obliga a redimirse y, al final de ese mismo capítulo, le dispara a una paloma con "todas sus funciones orgánicas suspendidas y concentrada", la despluma y la devora cruda. Señala el narrador:

Las plumas escupidas o arrancadas a puñados lo envolvieron en una nube que no se decidía a caer, y que siguió flotando mientras él se alejaba, con pantalones y botas emplumadas; la carne tibia, molida con toda la fuerza de las mandíbulas, resbalando por su esófago, y la sangre aguada, pachorruda, resbalando entre la barba naciente. (Chávez, 2012, p. 195)

Al respecto, llama la atención que el animal que mate sea una paloma, es decir, un pájaro que no representa mayor amenaza y resulta familiar no solo por su connotación urbana, sino también por ser símbolo de paz y del Espíritu Santo. La descripción tampoco ayuda a brindar un panorama más edificante de la situación.

Por otra parte, Luciano, a diferencia de sus desafortunados compañeros, encuentra refugio en una cueva de casualidad y allí permanece, en posición fetal, mientras más arriba lo buscan los soldados. Ellos son los agresores, no la naturaleza. La cueva es percibida inicialmente como un vientre materno, señala el narrador: "En el silencio y la penumbra de la cueva que lo apretaba con rigor y exactitud de vientre, sus botas se fueron apagando a medida que afuera subía el tono de las chicharras" (Chávez, 2012, p. 186). Sin embargo, rápidamente se desvanece esa idealización espacial. Luciano está consciente de su impotencia, del fracaso y, por ende, de la representación de este "renacimiento bufo" (Chávez, 2012, p. 187) que implica salir de la cueva por sus propios medios. En otras palabras, se distancia de esa metáfora de la naturaleza-madre también. Si él está allí, no es por ninguna fuerza cósmica. Se trata de una mala decisión, una pésima estrategia de combate. Nuevamente regresa al terreno de lo humano: "Él estaba prensado entre la raigambre de un árbol caído y la tierra sin color, oliente a vieja agónica" (Chávez, 2012, p. 187). Nótese además que el espacio se humaniza y, por la comparación con la agonía, se elimina toda idealización. De ahí que, mientras sale de la cueva, no pueda dejar de pensar en que es un "guerrillero que sale de nalgas" (Chávez, 2012, p. 189). Además, en su huida, se describe cómo ese espacio se mantiene indiferente a su drama humano:

\footnotetext{
Al levantar la vista vio la vasta ondulación cubierta de selva intocada, sumida en la animal expectación de un relámpago o de la conmoción sísmica que vendría a voltearla de raíces. Tal vez ni esperaba, y únicamente yacía en el sitio donde el viento había depositado las semillas, para que creciera y viviera en la muerte hasta la consumación de un segundo descubrimiento. (Chávez, 2012, p. 192)
}

En otras palabras, a diferencia de la asociación junguiana que señala Dennis Arias con respecto al espacio caribeño en Mamita Yunai de Carlos Luis Fallas (Arias, 2012, p. 80), en esta novela nicaragüense no hay una recreación del mito de la madre devoradora como origen del nacimiento y personalidad del héroe.

Asimismo, ni siquiera los animales son vistos como monstruos. Previo a la cita mencionada a continuación, la cuadrilla comandada por Luciano se interna en la selva con la misión de conseguir alimento para los revolucionados estacionados. Esta es la descripción de la muerte de la boa a la que le dispararon:

\footnotetext{
Atraída por el peso de la cabeza moribunda, la boa fue desplegándose y deslizándose sin perder el ritmo lento con que había vivido. Relucía al precipitarse en el vacío y caer entre la yerba, con el ruido de un ternero maniatado. Corrieron hacia donde había caído; la boa rodaba sobre sí misma hecha un tirabuzón gigantesco, en una poderosa y última constricción... (Chávez, 2012, p. 173)
}

Como se puede apreciar en esta cita, no se utilizan figuras de estilo que magnifiquen o exoticen la muerte de la boa. Todo lo contrario, la remiten al imaginario doméstico al comparar 
su caída con "el ruido de un ternero maniatado". Siguiendo esa misma lógica descriptiva, se narra cada encuentro con animales silvestres y domésticos en este capítulo. Ni siquiera los perros que usan para cazarlo una vez que la emboscada conjunta de la Guardia Nacional nicaragüense y el ejército hondureño se desata, son monstruos. Nuevamente se remite a su carácter doméstico: "ha de haber sido uno de esos animales precariamente prendidos a su esqueleto que pasan el día soñando bajo los fogones campesinos, o vagando por los solares vacíos de los pueblos..." (Chávez, 2012, p. 185). A diferencia de El Señor Presidente en el que se animalizan tanto los personajes, como el mundo en sí, incluyendo objetos y elementos naturales (Osorio, 2000, pp. 920-925); en este texto siempre se retorna al espacio humano.

En tercer lugar, a diferencia del ambiente demoniaco, irracional que se desprende tanto de la ciudad como de la cárcel, así como de los mismos personajes en El Señor Presidente, en el caso de la novela de Chávez los esbirros no se presentan como parte de un posible ambiente monstruoso. Durante la huida, los soldados que lo están cazando ni siquiera son descritos. El foco cero se concentra en Luciano y se limita a narrar cómo percibe la realidad circundante. Dependemos de los sentidos de Luciano. De los soldados, nosotros los lectores, solo alcanzamos a escuchar susurros, a ver pasar sombras en la noche. Se repiten las palabras asociadas a ese campo semántico de la indefinición de los sentidos. Esta ausencia de los soldados, a pesar de estar en plena refriega, se refuerza al limitarse al mínimo posible los intercambios verbales entre Luciano y ellos.

En suma, el texto no presenta metáforas biopolíticas y, en ese sentido, se aleja de la explotación ontológica y metafórica de los animales que suponen generalmente la concepción de lo monstruoso y también de lo mítico. Sin embargo, tampoco se podría asumir que se trata de una postura posthumanista en el sentido de que no le interesa reconfigurar la relación del ser humano con el espacio y con los animales con los cuales convive (Yelin, 2013). Chávez no va más allá de centrar lo monstruoso en el terreno de lo humano y sus leyes. Se trata simplemente de una postura en la que constantemente se enfatiza el constructo social y se evita revestirla de otra cosa que no sea la misma humanidad y su intervención del espacio.

En ese sentido es importante acotar el simbolismo que adquiere el hecho de que este enfrentamiento entre el grupo revolucionario y las fuerzas represivas militares se dé entre Honduras y Nicaragua, dado el significado que se le otorga a la frontera como marcador de naciones. Como señala Segade en su artículo acerca de lo monstruoso en textos literarios sobre la guerra de las Malvinas, estas se construyen como frontera: "zona de disputa y de contacto, al mismo tiempo adentro y afuera de la nación, límite y umbral de la "comunidad imaginada", (Segade, 2014, pp. 233-234). Esa observación bien vale para la frontera entre Honduras y Nicaragua. La frontera es el umbral que separa la vida burguesa a la que podría aspirar y la lucha por la nación nicaragüense tal y como él la entiende.

\section{Lo monstruoso-moral de Luciano}

Ante la imposibilidad de construir una subjetividad heroica encarnada en Luciano y de representar un espacio signado por lo monstruoso para representar la otredad política, la novela concentra su fuerza en aquello que definitivamente es humano: la ley, la nación, la violencia verbal. Dicho de otro modo, Trágame tierra no juega con la oscilación entre familiar y extraño a partir de la dicotomía normal-anormal, sino que nos revela la familiariedad y la extrañeza que implica de por sí aquello que consideramos normal, humano. No se utiliza al espacio o a los animales de manera especular, de una vez nos vemos reflejados en nuestra inherente extrañeza y familiariedad. 
Como primer punto me interesa destacar el intercambio verbal entre Luciano Pineda e Ismael Sánchez. Amigos de infancia y desde entonces asiduos a los pleitos y a la sangre, se encuentran en el presente como preso y carcelero respectivamente. Puesto de otra manera, la dictadura no se encarna en un personaje lejano a Luciano, sino que se trata de su vecino, de alguien que lo conoce desde la niñez. Es importante tomarlo en cuenta pues el hecho de que sean contemporáneos y que vengan del mismo lugar elimina la posibilidad de demonizar justamente aquello que comparten. En consecuencia, no hay posibilidad de que Ismael o Luciano se presenten claramente como monstruos ante el lector. El contraste es vital para revelar la precariedad de la vida (Segade, 2014, p. 217) y el monstruo supondría por rebote la valoración de la regularidad morfológica, de la estructuración a la que nos hemos habituado.

Retomando la oposición binaria decimonónica, se recrea una vez más y por parte de ambos contendientes la división civilización-barbarie. Según Ismael, Luciano es "un criminal que corre de mata en mata con una banderita de papel en la que dice muerte"; mientras que él representa paz, orden, autoridad y respeto. En otras palabras, Ismael se presenta como responsable de preservar la ley. El capitán se siente identificado con ese orden y esa jerarquía en pro de que esa comunidad, ese "nosotros" pueda "gozar ordenadamente de los beneficios de la tierra” (Chávez, 2012, p. 245). Por esa razón, Ismael le señala: "Aquí se trabaja a conciencia por el progreso y se aparta a conciencia a quienes lo estorban" (Chávez, 2012, p. 242). Ante esa lógica, las acciones de Luciano no son más que un ejemplo claro de "violencia animal" que desafía "la Autoridad de la inteligencia, la fuerza del orden natural” (Chávez, 2012, p. 245).

Asimismo, el origen de la monstruosidad de Luciano se la endilga el capitán Sánchez al padre. Según Sánchez, Plutarco no supo cómo educarlo ni cómo hacerse respetar. El capitán sabe que no le está diciendo esas palabras duras a cualquiera, no se trata de un simple abuso de poder. Es más, la crítica de Sánchez es la misma de la madre de Luciano, quien reniega a su hijo por el sufrimiento que le ha causado a ella y a sus dos hijas por no asumir su rol de "ser hombre y defender su casa" (Chávez, 2012, p. 254). Incluso César Barrantes, quien ha asumido el lugar de Luciano en el hogar de los Pineda, reclama la ingratitud del "farsante". En definitiva, el concepto de casa de Luciano trasciende las cuatro paredes, pero en esa conceptualización abstracta de Nicaragua deja totalmente de lado todo lazo familiar. De ahí que lo tilden repetidas veces de egoísta.

Por su parte, para Luciano, no se trata de ejercer una violencia animal, sino de violencia purificadora. En pleno interrogatorio con Ismael, le señala que quiere limpiarse (Chávez, 2012, p. 242), atendiendo así la caracterización de la revolución sandinista como "cierre de época que posee poder purificador sobre el pasado" al cual se refiere Delgado (2013/2014, p. 1). Esa violencia es necesaria para rechazar esa paz que no le interesa, esas condiciones serviles y purificar a Nicaragua. Eso implica superar sus propios miedos, dominar sus reacciones, trascenderlas con el fin de sobrevivir y así emerger con una nueva serie de valores. De ahí que, cuando se encuentra en la montaña, Luciano reflexiona e indica que no puede hacer más que aislarse "de esa tabla de mandamientos" (Chávez, 2012, p. 198), es decir, de esa guía de comportamiento social que también lo permea, para luchar por el establecimiento de una nueva ley.

Esa necesidad de redención es tan radical, tan pasional que supone una ruptura total con el padre y la familia. Luciano señala en numerosas ocasiones la necesidad de redimir la 
vergüenza que le provoca su padre y sus decisiones, su cobardía por aliarse con las compañías transnacionales y darle la espalda a Sandino. El único honor por el cual este guerrillero se dispone a luchar es por el de Nicaragua. Señala el narrador acerca de la percepción de Luciano, en los últimos días de su vida, acerca de su padre:

\footnotetext{
[...] un viejo simulador del arrepentimiento (arrepentido tal vez hasta de haberlo engendrado); aferrador al mito de una magna obra de caridad que, ordenada desde las alturas, vendría a bañar de riqueza a él y a todos los suyos, y finalmente, un padre viejo que ni siquiera tenía la nobleza de desintegrarse de una vez por todas y dejarlo solo con su mamá 'violencia'. (Chávez, 2012, p. 270)
}

El padre ha hecho hasta lo imposible por ver a su hijo e intentar salvarlo de una muerte segura, pero Luciano se resiste e incluso cuando el padre encuentra la manera de entrar en su celda, se mantiene en absoluto silencio durante los 15 minutos de la visita. Ese comportamiento antisocial, da pie a la siguiente observación por parte de uno de sus carceleros: "No sea animal; es su padre, carajito de mierda" (Chávez, 2012, p. 268). En ese sentido es importante marcar que Plutarco, con tal de sobornar a las autoridades, vende ese preciado pedazo de tierra que ha constituido la esperanza de una mejor vida para su familia. Se deshace de la ilusión de la riqueza por recuperar una vez que se construya el ansiado canal de Nicaragua y su acción no resuena en Luciano. El padre demuestra ser capaz del mayor de los desprendimientos y Luciano es incapaz de escucharlo. Luciano se niega entonces a cumplir con el mandamiento "honrarás a tu padre y a tu madre", y eso supone una confirmación de monstruosidad revolucionaria para sus contrincantes porque Luciano no da indicios de sentir culpa, de comprender o asimilar su rol de hijo.

La asociación entre la ley de la dictadura y el cumplimiento de los mandamientos es tal que quien le da refugio a Luciano termina delatándolo por la presión de cumplir el mandamiento "no mentir". El campesino, al pasar frente a la delegación del pueblo, no puede controlar las reacciones de su cuerpo por el ocultamiento del guerrillero: escucha murmuraciones, risas, le arden la cara y los dedos, siente náuseas. Su culpa llega a tal punto que se siente preso y claudica su intento de ayudar a Luciano. Señala el narrador: "[...] ahora sabía que la cosa no era tan fácil como mentir o no mentir, sino a quién y para quién mentir" (Chávez, 2012, p. 207).

Asimismo, en el sistema moral de Luciano es más asqueroso y abyecto que Chester, uno de los guerrilleros de su cuadrilla, use un nombre en inglés que el destace de la boa:

\footnotetext{
Luciano movía la cabeza, a veces nada más los ojos, de abajo hacia arriba, del animal muerto al animal vivo [Chester] que hablaba frente a él, en una especie de asco creciente y necesario. Todos fruncieron la cara y sacaron la lengua cuando el puñal corrió a lo largo del vientre de la boa, excepto Luciano, ocupado en un asco anterior y más real. (Chávez, 2012, p. 174)
}

Se evidencia cómo para este personaje lo monstruoso se relega al plano de lo humano, de lo simbólico-verbal por lo que representa el nombre propio del guerrillero. Desde ese punto de vista, Luciano es totalmente consecuente pues, como ya se mencionó, sus padres lo habían bautizado Ronald y a fuerza de insistencia todos terminaron llamándolo Luciano, nombre escogido por él mismo. Aunque Chester aclara que se llama así en honor a un aviador estadounidense que le salva la vida a su familia en medio de una ofensiva contra Sandino y sus hombres en 1931, eso no impide que Luciano le espete que los nombres no son inocentes (Chávez, 2012, p. 180).

Siguiendo los planteamientos de Walter Benjamin en su célebre "Crítica de la violencia", se plantea entonces una violencia que preserva la ley y otra que intenta hacer ley, 
las cuales se asocian respectivamente con las posturas de Ismael y Luciano. Ante los insultos del carcelero, Luciano piensa para sus adentros, parafraseando pero sin señalarlo así el ciclo al cual alude Benjamin:

\section{[...] te falta saber que la otra mitad tiene locura de sobra para seguir violando tus leyes hasta que la violación se levante como nueva ley. Sucede que los elegidos de cualquier tiempo nacen para ser devorados por los elegidos del siguiente. (Benjamin, 1979, p. 245)}

El problema de fondo con esta postura, siempre siguiendo a Benjamin, es que, en la novela, no hay tal violencia purificadora (divina). La violencia que Luciano busca es una violencia mítica, sangrienta, que busca desestabilizar la ley, pero sin claridad en cuanto al futuro por construir. A diferencia de lo que los demás encarcelados pretenden conseguir como “cambio total", Luciano sólo tiene necesidades concretas y admite que, tal vez, ellos sí tienen las "verdaderas armas" (Chávez, 2012, p. 272), pero la descripción de sus motivaciones deja mucho que desear. En definitiva, no hay todavía una fuerza homogénea, clara en sus propósitos en contra de la dictadura ni clara en sus objetivos de justicia. No se vislumbra una posible violencia divina a la Benjamin que venga a inaugurar una nueva época.

Además, aunque Héctor Leyva señala que se desprende una sensibilidad distinta en los jóvenes a través de Luciano como de César Barrientos (Leyva, 2002, p. 119), es importante destacar que no todos son ejemplo de dicha sensibilidad, pues Ismael Sánchez es contemporáneo de Luciano y César. En ese sentido, llama la atención cómo esta novela, por su percepción del movimiento revolucionario y la manera en que se divide la sociedad, augura problemas sociales que se agudizan en el pos-triunfo y la pos-derrota en Centroamérica. A fin de cuentas, quienes se enfrentan son los muchachos del barrio, padres e hijos, hermanos y hermanas, guerrilleros entre sí. En pocas palabras, Trágame tierra de Lizandro Chávez, al construir una concepción de lo monstruoso que gira, ya no en función de la otredad, sino la mismidad de la condición humana, no pierde su vigencia.

En síntesis, la novela presenta un panorama ambiguo. Este ejercicio exploratorio, muestra cómo el conflicto y lo monstruoso de la violencia anida en el ámbito de lo humano. El espacio y los animales son ajenos al drama humano, pues el drama gira en función de la ley y los mandamientos. Dado que, desde el punto de vista somocista, es monstruo quien suspende su cumplimiento, la resistencia adquiere carácter monstruoso. Es la posibilidad de cambio, la exploración de una verdadera ruptura con el orden social hasta entonces conocido lo que adquiere esas características. Desde el punto de vista revolucionario, es monstruoso quien no lo rompe.

En vez de haber un marco referencial de regularidades contra el cual proyectar el fenómeno para destacar su anomalía, lo que se presenta es la imposibilidad de definir un código ideológico que integre nociones elementales de lo bueno/lo malo, lo positivo/lo negativo, etc., y que, así, nos permita una clara definición de lo monstruoso. No hay, como sí se presenta en El Señor Presidente por ejemplo, una concreción mítica de dichas categorías abstractas en función de lo divino y lo demoníaco (Osorio, 2000, p. 920). Luciano no es de ninguna manera el correlato mítico del ángel caído como sí lo es Cara de Ángel en la novela de Asturias (Osorio, 2000, p. 926). No funciona por tanto como correlato de normalidad ante un eventual carácter teratológico de la sociedad somocista. En ese sentido, el texto de Chávez permite que aflore un saber positivo, es decir, retomando las palabras de Gabriel Giorgi acerca del monstruo, el reconocimiento de la capacidad de variación humana (Giorgi, 2009, p. 323). Lo monstruoso es familiar, está entre nosotros, pues somos monstruosos. 


\section{Epílogo}

En cierto sentido, la novela recoge una sensación de no saber cómo proceder, recrea un momento primigenio de caos. De hecho, a pesar de publicarse en 1969, la novela plantea un momento casi de inauguración de la resistencia contra la dictadura somocista, pues la trama se sitúa a finales de la década de los años cincuenta. El texto recrea los acontecimientos de la ofensiva fracasada de El Chaparral que se organizó algunos meses después del triunfo cubano de 1959 (Leyva, 2002, p. 115). Llama por tanto la atención que el texto centre en la ficcionalización de dicho fracaso, aunque tal vez no sea casualidad. En 1969, acababa de morir asesinado el Che y ya era claro que la estrategia rural emprendida en Nicaragua había fracasado. Además, no había en ese momento una identificación colectiva con la lucha ni tampoco se había logrado cooptar de manera coherente la figura de Sandino (Palmer, 1988). Estamos muy lejos del punto de quiebre que significó el terremoto de Managua de 1972. Mal que bien la sociedad nicaragüense aguantó varias décadas la dictadura y, como lo señala Waldmann (1986, p. 6), su permanencia se relaciona con un largo historial de caudillismo.

Retomando la reflexión sobre el orden que se busca preservar y violentar simultáneamente, el dilema consiste en que las muertes de Luciano y César, ${ }^{4}$ así como la caracterización de los revolucionarios encarcelados, no apuntan hacia el establecimiento pronto de un orden justo. Más bien, siempre en comparación con El Señor Presidente, pareciera que en esta novela de Lizandro Chávez también se reestablece un orden injusto y anormal, pero orden al fin. En pocas palabras, no está en claro cómo entender o construir lo que significaría un "hombre nuevo", una Nicaragua nueva, alejada del orden somocista. De la novela no se puede extraer un panorama de cómo sería el futuro según los revolucionarios, no hay una construcción teleológica como la demostrada por Laura Barbas Rhoden (1999) con respecto a La montaña es algo más, pues según la académica esta se escribe con el fin de generar simpatía para la hegemonía sandinista en el poder.

Ante esa incertidumbre, se suspende la asociación entre discurso político y metáforas de lo monstruoso que resulta tan productiva en la filosofía política que, como señala Juan Cristóbal Revueltas, difícilmente puede "limitarse al discurso demostrativo, ella requiere también de la retórica literaria y visual debido a la naturaleza intersubjetiva de lo político" (Revueltas-Cruz, 2008, p. 9). La manera en que se representa la otredad política en esta novela se distancia entonces de la orientación de gran parte de las textualidades narrativas centroamericanas de los sesentas y los setentas. Estas, según Arturo Arias, "fueron concebidas como una variedad de discursos re-fundacionales para esas 'nuevas naciones' a ser construidas por medio de luchas revolucionarias" (Arias, 2013/2014, p. 17). Al no haber una subjetividad heroica y no haber tono épico, más que una re-fundación de Nicaragua lo que se presenta es una lectura sumamente contradictoria acerca del futuro de la revolución.

\section{Notas}

1. Importante señalar que inicialmente el movimiento que se está conformando no estaba de acuerdo con retomar la figura de Sandino, es decir, con incorporar raíces históricas-nacionales en la ideología. Palmer señala que el proceso revolucionario cubano inspiró a Fonseca y dictó la formación del FSLN en la década de los sesenta. La tensión referida en el párrafo anterior siguió siendo palpable y Fonseca trabajó arduamente en hacer que Sandino se integrara a la ideología revolucionaria de base marxista. Hizo ese trabajo desde 1960 hasta su muerte en 1976 (Palmer, 1988).

2. En el plano caribeño que protagoniza César Barrantes, sí se aborda el tema de la diversidad sexual, del honor y la familia. 
3. En esta batalla que se llevó a cabo cerca de la frontera entre Nicaragua y Honduras, una columna formada por veteranos de las campañas de Sandino y por jóvenes radicales fue emboscada y masacrada por la guardia nicaragüense en conjunto con la hondureña. La noticia de la masacre tuvo repercusiones importantes pues al menos cuatro estudiantes de la Universidad Nacional murieron en una protesta posterior (Beverley y Zimmerman, 1990).

4. Como indica César Leyva, una vez que se da cuenta de que el sargento del pueblo deshonró a Amanda, la hermana de Luciano, decide vengarla. Se le enfrenta y lo mata el sargento. Su "comportamiento anormal contradice las costumbres. Es como Luciano un subvertidor del orden. Con sus gestos humanitarios intenta redimir ofensas y su sensibilidad es ya de por sí una protesta" (Leyva-Carías, 2002, p. 118).

\section{Bibliografía}

Arias, A. (2013/2014). ¿De veras agotadas? Solo en el mercado por su falta de circulación: repensando la narrativa centroamericana del mini-boom. Istmo. Revista virtual de estudios literarios y culturales centroamericanos. (27-28), 1-21. http://istmo.denison. edu/n27-28/articulos/02.html [Consulta 28 de junio de 2015].

Arias, D. (2012). El viaje del héroe al espacio monstruoso: metáforas de un saber biopolítico hecho novela. Revista CS. 9, 55-86.

Barbas-Rhoden, L. (1999). El papel del testimonio después de la victoria: Omar Cabezas y el discurso revolucionario en Nicaragua. Confluencia. 14 (2), 63-75. DOI: $10.2307 / 27922690$.

Benjamin, W. (1979). Critique of Violence. One-way street and other writings. (132-154). London: NLB.

Beverley, J. y Zimmerman, M. (1990). Literature and politics in the Central American revolutions. New interpretations of Latin America series. Austin: University of Texas Press.

Chávez, L. (2012). Trágame tierra. Managua: Anama.

Delgado-Aburto, L. (2011). El caribe nicaragüense en textos de la literatura nacional moderna: de la civilización protectorista a la mulatidad global. América Latina Hoy. 58, 63-80.

Delgado-Aburto, L. (2013/2014). La memoria travestida: Caribe, estética e historia en Trágame tierra de Lizandro Chávez Alfaro. Istmo. Revista virtual de estudios literarios y culturales centroamericanos. (27-28), 1-14. http://istmo.denison.edu/ [Consulta 28 de junio de 2015].

García, Ó. (2013). Machismo y revolución: La figura del guerrillero y la construcción de la masculinidad en novelas centroamericanas. Por M. Albizúrez-Gil y A. Ortiz (Eds.). Poéticas y políticas de género. (117-140). Berlin: Edition Tranvía.

Giorgi, G. (2009). Introducción-Política del monstruo. Revista Iberoamericana. 75 (227), 323329. DOI: 10.5195/reviberoamer.2009.6575.

Grinberg, V. y Mackenbach, W. (2006). Banana novel revis(it)ed: etnia, género y espacio en la novela bananera centroamericana. El caso de Mamita Yunai. Iberoamericana. 6 (23), 161-176. DOI:10.2307/41676099

Jing, X. (2010). Sacrificio sublime, sacrificio obsceno. La fundación del cuerpo nacional en "La cautiva" y "El matadero" de Esteban Echevarría. Por R. Folger y S. Leopold (Eds.). Escribiendo la independencia. Perspectiva postcoloniales sobre la literatura hispanoamericana del siglo XIX. (97-124). Madrid/Frankfurt am Main: Iberoamericana/ Vervuert. 
Leyva-Carías, H. (2002). La novela de la revolución centroamericana (1960-1990). (Tesis doctoral). Universidad Complutense de Madrid. http://eprints.ucm.es/ [Consulta 29 de junio de 2015].

Meneses, V. (1982). El aire que me llama. Managua: Unión de Escritores de Nicaragua e IMELSA.

Osorio, N. (2000). Lenguaje narrativo y estructura significativa de El Señor Presidente de Asturias. Por G. Martin (Ed.). El Señor Presidente. (865-929). Barcelona: ALLCA XX.

Palmer, S. (1988). Carlos Fonseca and the Construction of Sandinismo in Nicaragua. Latin American Research Review. 23 (1), 91-109. DOI: 10.2307/2503321 [Consulta 02 de julio de 2015].

Perkowska, M. (2013/2014). Introducción: ¿Narrativas agotadas o recuperables? Relecturas contemporáneas de las ficciones de los sesenta y setenta. Istmo. Revista virtual de estudios literarios y culturales centroamericanos. (27-28), 1-23. http://istmo.denison. edu/ [Consulta 28 de junio de 2015].

Revueltas-Cruz, J. C. (2008). La imagen del Estado moderno: del gran hombre a lo sublime y lo monstruoso. Signos Filosóficos. 20, 9-24. http://search.ebscohost.com/ [Consulta 14 de setiembre de 2014].

Rodríguez, I. (1988). La narrativa nicaragüense durante los años de formación del FSLN. Casa de las Américas. 29 (170), 117-121.

Saldaña-Portillo, M. J. (2003). The Revolutionary Imagination in the Americas and the Age of Development. Durham, N.C.: Duke University Press.

Schmidt-Welle, F. (2012). Regionalismo abstracto y representación simbólica de la nación en la literatura latinoamericana de la región. Relaciones (Zamora). 33, 115-127. http://www. scielo.org.mx/ [Consulta 15 de julio de 2015].

Segade, L. (2014). Lo monstruoso, lo siniestro y lo grotesco en algunos relatos de guerra: las Malvinas como frontera. Cuadernos de Literatura. 18 (36), 211-236.

Vargas, V.J.(2003). Superación del regionalismo y conciencia escritural en la novelacentroamericana contemporánea. InterSedes: Revista de las Sedes Regionales. 4 (6), 109-124.

Waldmann, P. (1986). La revolución nicaragüense: la antigua y la nueva guerrilla de América Latina. Anuario de Estudios Centroamericanos. 12 (1), 5-24. DOI:10.2307/25661879 [Consulta 02 de julio de 2015].

Yelin, J. (2013). Para una teoría literaria posthumanista. La crítica en la trama de debates sobre la cuestión animal. e-misferica. 10 (1). http://hemisphericinstitute.org/ [Consulta $01 \mathrm{de}$ julio de 2015]. 